\title{
Imagem MoleculaR: A Importância dos Metals
}

\author{
M. Isabel Prata \\ ICNAS e IBILI - Universidade de Coimbra \\ mimprata@uc.pt
}

\begin{abstract}
As técnicas de imagem molecular, nomeadamente as técnicas de Medicina Nuclear, têm vindo a adquirir importância crescente quer no diagnóstico médico quer no seguimento da terapêutica, abrindo caminho à denominada "medicina personalizada”. Em Medicina Nuclear utilizam-se muitas vezes, como sondas radioactivas, moléculas que contêm radioisótopos metálicos e é destes isótopos e das moléculas que os transportam, desde moléculas de baixo peso molecular aos grandes anticorpos, que trata este artigo.
\end{abstract}

\section{INTRODUÇÃO}

A imagem molecular pretende visualizar moléculas e eventos moleculares que ocorrem ao nível celular, com o objectivo último de detectar anomalias a esse nível antes que essas anomalias se traduzam em sintomas clínicos.

Para atingir esse objectivo usam-se sondas moleculares específicas para cada um desses eventos. Muitas dessas sondas contêm iões metálicos radioactivos e é deles que iremos tratar ao longo deste artigo. Uma das maiores diferenças entre a química “clássica” dos iões metálicos e a química dos radioisótopos metálicos é que em radioquímica trabalhamos em condições de extrema diluição, normalmente em concentrações que vão do nano ao picomolar.

Quando falamos de imagem molecular em Medicina Nuclear estamos essencialmente a referir dois paradigmas diferentes de obtenção de imagem: tomografia a partir de isótopos emissores de fotão simples - SPECT (da designação inglesa, single photon emission computed tomography) ou de emissores de positrões - PET (da designação inglesa positron emission tomography).

Ambas as técnicas possuem uma muito elevada sensibilidade. Uma molécula marcada com um radionuclídeo emissor de positrões ou de fotões gama é, tipicamente, injectada no paciente e transportada para o local de interesse através da corrente sanguínea. O paciente é colocado no tomógrafo PET ou SPECT e um conjunto de cintiladores externos, constituídos por cristais (e.g. de $\mathrm{NaI}(\mathrm{Tl})$ para SPECT; de oxiortossilicato de lutécio (LSO) para PET) detecta os fotões emitidos directamente pelo radionuclídeo (SPECT) ou os pares de fotões resultantes da aniquilação do positrão (PET).

O conjunto destes eventos detectados é tratado utilizando algoritmos de reconstrução e correcção de imagem dando origem a mapas de distribuição do radiofármaco no corpo do paciente [1].

A escolha do radionuclídeo a utilizar depende em primeiro lugar da aplicação pretendida (SPECT, PET, terapêutica) e em seguida da sua química de incorporação no composto seleccionado. Uma vez estabelecida a aplicação e a química, a escolha do radionuclídeo depende, para além do seu custo e facilidade de obtenção, de características que lhe são intrínsecas tais como, período de semi-desintegração, esquema de decaimento e energias dos fotões ou partículas emitidas.

O período de semi-desintegração de um radionuclídeo deve ser suficientemente longo de modo a permitir a produção do radiofármaco e obtenção da imagem, mas não tão longo que torne a sua dosimetria desfavorável para o doente.

A energia deve ser adequada ao sistema de detecção a ser utilizado: no caso das câmaras de SPECT os raios $\gamma$ devem ter valores de energia entre 100 e $250 \mathrm{keV}$. Fora desta gama de energia as imagens são de fraca qualidade e/ou apresentam uma dosimetria desfavorável para o paciente.

O esquema de decaimento dos radionuclídeos é também muito importante. Assim, se no caso dos radiofármacos destinados à terapêutica a emissão $\beta^{-}$ou $\alpha$ é necessária, já no que diz respeito a moléculas para diagnóstico a presença de emissão de partículas é fortemente desfavorável, pois contribui para a dose de radiação no paciente sem representar qualquer utilidade na formação da imagem.

Embora o ${ }^{99 m}$ Tc continue a ser o radioisótopo mais utilizado em Medicina Nuclear [2], um grande número de radioisótopos metálicos tem encontrado aplicação quer em diagnóstico quer em terapêutica [3-6]. A Tabela 1 apresenta as propriedades nucleares de um conjunto de radioisótopos metálicos utilizados em clínica [3]. 
Tabela 1 - Propriedades de alguns isótopos radioactivos metálicos utilizados em imagem ou terapêutica [3] (IT - transição isomérica, EC- captura electrónica)

\begin{tabular}{|c|c|c|c|c|c|}
\hline Isótopo & $t_{1 / 2}$ & Modo de decaimento & Energia (keV) & Método de Produção & Utilização \\
\hline${ }^{99 \mathrm{~m}} \mathrm{Tc}$ & $6,01 \mathrm{~h}$ & IT(89\%) & ү 141 & Gerador ${ }^{99} \mathrm{Mo} /{ }^{99 \mathrm{~m}} \mathrm{Tc}$ & SPECT \\
\hline${ }^{67} \mathrm{Ga}$ & $78,2 \mathrm{~h}$ & $\mathrm{EC}(100 \%)$ & ү 93,184,300 & Ciclotrão ${ }^{68} \mathrm{Zn}(\mathrm{p}, 2 \mathrm{n}){ }^{67} \mathrm{Ga}$ & SPECT \\
\hline${ }^{68} \mathrm{Ga}$ & 67,71 min & $\begin{array}{l}\beta^{+}(90 \%) \\
\operatorname{EC}(10 \%)\end{array}$ & $\beta^{+} 1880$ & Gerador ${ }^{68} \mathrm{Ge} /{ }^{68} \mathrm{Ga}$ & PET \\
\hline${ }^{111}$ In & $67,2 \mathrm{~h}$ & $\mathrm{EC}(100 \%)$ & ү 93,184,300 & Ciclotrão ${ }^{111} \mathrm{Cd}(\mathrm{p}, \mathrm{n})^{111} \mathrm{In}$ & SPECT \\
\hline${ }^{64} \mathrm{Cu}$ & $12,7 \mathrm{~h}$ & $\begin{array}{l}\beta^{+}(19 \%) \\
\operatorname{EC}(41 \%) \\
\beta^{-}(40 \%)\end{array}$ & $\beta^{+} 656$ & Ciclotrão ${ }^{64} \mathrm{Ni}(\mathrm{p}, \mathrm{n}){ }^{54} \mathrm{Cu}$ & PET \\
\hline${ }^{44} \mathrm{Sc}$ & $3,9 \mathrm{~h}$ & $\begin{array}{l}\beta^{+}(94 \%) \\
\operatorname{EC}(6 \%)\end{array}$ & $\beta^{+} 1474$ & Gerador ${ }^{44} \mathrm{Ti} /{ }^{44} \mathrm{Sc}$ & PET \\
\hline${ }^{82} \mathrm{Rb}$ & $1,27 \mathrm{~m}$ & $\beta^{+}(96 \%)$ & $\beta^{+} 1168,1535$ & Gerador ${ }^{82} \mathrm{Sr} /{ }^{82} \mathrm{Rb}$ & PET \\
\hline${ }^{89} \mathrm{Zr}$ & $78,5 \mathrm{~h}$ & $\begin{array}{l}\beta^{+}(25 \%) \\
\operatorname{EC}(77 \%)\end{array}$ & $\beta^{+} 897$ & Ciclotrão ${ }^{89} \mathrm{Y}(\mathrm{p}, \mathrm{n})^{89} \mathrm{Zr}$ & PET \\
\hline${ }^{90} \mathrm{Y}$ & $64,1 \mathrm{~h}$ & $\beta^{-}(100 \%)$ & $\beta-2280$ & Reactor ${ }^{90} \mathrm{Zr}(\mathrm{n}, \mathrm{p})^{90} \mathrm{Y}$ & terapêutica \\
\hline${ }^{177} \mathrm{Lu}$ & $159,4 \mathrm{~h}$ & $\beta^{-}(100 \%)$ & $\beta^{-177,385,498}$ & Reactor ${ }^{176} \mathrm{Lu}(\mathrm{n}, \gamma){ }^{177} \mathrm{Lu}$ & terapêutica \\
\hline
\end{tabular}

\section{Quelatos em Medicina Nuclear}

Um dos critérios fundamentais na introdução de um radioisótopo num traçador PET ou SPECT é que este não produza alterações significativas nas propriedades físico-químicas da molécula, o que se verifica com os isótopos emissores de positrões ${ }^{11} \mathrm{C},{ }^{13} \mathrm{~N}$ e ${ }^{15} \mathrm{O}$ e, em menor medi$\mathrm{da}$, com $0{ }^{18} \mathrm{~F}$ utilizados em traçadores PET. No entanto, o período de semi-desintegração relativamente curto destes radioisótopos, aliado à necessidade de uma química mais laboriosa, comprometem o número de moléculas que, efectivamente, podem ser assim marcadas. Daí a necessidade de se recorrer a quelatos de iões metálicos emissores de positrão ou de fotão simples. O ligando é utilizado para coordenar eficazmente o metal não permitindo a sua libertação nem a sua hidrólise. Estes quelatos de radioisótopos podem ser introduzidos directamente na corrente sanguínea, sendo a sua localização e distribuição determinada pelas suas propriedades físico-químicas, tais como o grau de hidrofilicidade, peso molecular, capacidade de ligação a proteínas plasmáticas, entre outras. Ou podem servir para marcar moléculas biológicas que interagem com estruturas celulares. Neste último caso, designam-se por quelatos bifuncionais. Os quelatos bifuncionais (Figura 1) consistem em ligandos polidentados capazes de formar complexos de elevada estabilidade termodinâmica e cinética com o metal escolhido e, através de grupos funcionais tais como amina $\left(-\mathrm{NH}_{2}\right)$, carboxilato $\left(-\mathrm{CO}_{2} \mathrm{H}\right)$ ou isotiocianato (-NCS), podem ser covalentemente ligados a moléculas biologicamente activas (e.g. peptídeos, anticorpos) [7].

Convém realçar que mesmo integrado numa molécula maior (peptídeo, nucleotídeo, anticorpo), que interaja com estruturas celulares, a escolha do quelante a utilizar tem enorme importância já que pode modificar a biodis- tribuição do bioconjugado. Foi verificado que, no caso de peptídeos, mantendo toda a molécula igual mas variando o quelante, a sua biodistribuição pode ser drasticamente diferente [8].

\section{Tecnécio-99m: Produção, Química e Radiofármacos}

Na tabela periódica o tecnécio (Tc) é o elemento 43, um metal de transição. O seu nome vem do grego technetos que significa artificial. Todos os isótopos do tecnécio são radioactivos. O tecnécio tem uma química completamente diferente da dos demais radioisótopos metálicos que aqui serão tratados [9] e, normalmente, surge na literatura em publica-
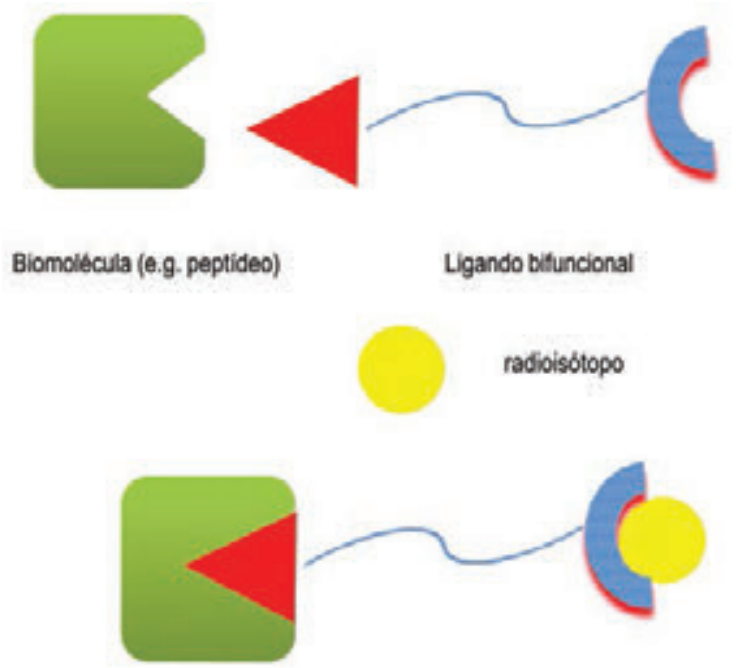

Bioconjugado marcado com um radioisoblopo

Figura 1 - Esquema dos quelatos bifuncionais: um ligando polidentado que coordena o metal permite também a ligação covalente a moléculas biologicamente activas (e.g. peptídeos, anticorpos, etc.) 
ções independentes. No entanto, por se tratar de um metal, e pela sua importância em Medicina Nuclear, entendeu-se fazer aqui uma, ainda que breve, referência à química do tecnécio e aos seus radiofármacos. Para mais informação sobre radiofármacos contendo ${ }^{99 \mathrm{~m}} \mathrm{Tc}$ e/ou sobre a química do tecnécio, dispõe o leitor de excelentes artigos de revisão $[9,10]$.

O ${ }^{99 m}$ Tc é o radioisótopo mais utilizado em Medicina Nuclear e isso deve-se às suas excelentes propriedades nucleares: emite radiação $\gamma$ de 140 keV numa abundância de 89\%, características quase ideais, quer do ponto de vista da qualidade da imagem, quer do ponto de vista da dose de radiação para o paciente e tem um período de 6,01 h, o que facilita a preparação e controlo de qualidade dos seus radiofármacos, e subsequente aquisição de imagem, mesmo que em protocolos mais complexos. A grande popularidade do ${ }^{99 \mathrm{~m}} \mathrm{Tc}$ deve-se também ao facto de poder ser produzido diariamente in situ através de um gerador ${ }^{99} \mathrm{Mo} /{ }^{99 m} \mathrm{Tc}$. Os geradores de radionuclídeos, aos quais se irá voltar ao longo deste artigo, baseiam-se na existência de um radionuclídeo "pai” de período longo que decai para um radionuclídeo “filho” com um período curto. Neste caso o "pai” é o ${ }^{99} \mathrm{Mo}\left(\mathrm{t}_{1 / 2}=66\right.$ dias) e o radionuclídeo "filho" o ${ }^{99 m} \mathrm{Tc}\left(\mathrm{t}_{1 / 2}=6,01 \mathrm{~h}\right)$. Para que este sistema "pai/filho” possa ser utilizado é necessário que se conheça um método expedito de separar os dois radionuclídeos.

Os geradores comerciais ${ }^{99} \mathrm{Mo} /{ }^{99 m} \mathrm{Tc}$ contêm molibdato (de sódio) radioactivo adsorvido numa coluna de óxido de alumínio. O ${ }^{99 \mathrm{~m} T c}$ que se vai formando continuamente na coluna não tem a mesma afinidade química para a alumina que o molibdato, pelo que pode ser extraído, na forma de pertecnetato $\left({ }^{99 \mathrm{~m}_{\mathrm{TcO}}^{-}}{ }_{4}\right)$ por eluição com soro fisiológico. A obtenção de radiofármacos de ${ }^{99 m}$ Tc é ainda facilitada pela existência de kits comerciais liofilizados contendo a formulação adequada à rápida formação dos complexos por adição de ${ }^{99 m}$ Tc na forma de pertecnetato. No entanto, o ${ }^{99 m}$ Tc eluído do gerador nessa forma, possui número de oxidação +7 , e não complexa com a maioria dos ligandos, necessitando de ser reduzido através da reacção com um agente redutor. Com esse fim são vulgarmente utilizados como redutores o cloreto de estanho(II) ou o ácido clorídrico. Após a redução, e na presença dos ligandos adequados, o ${ }^{99 m}$ Tc passa a ter estados de oxidação que vão de -1 a +6 , dependendo das características do redutor, das condições de reacção e do(s) ligando(s) que coordenam o metal. Se, por um lado, a possibilidade de o ${ }^{99 m}$ Tc poder existir em todos estes estados de oxidação dificulta o controlo das reacções e aumenta a labilidade dos complexos formados, por outro oferece mais oportunidades de modificação da estrutura e propriedades dos complexos através da escolha dos ligandos apropriados [11]. Outra característica importante dos compostos de tecnécio é a possibilidade de nestes existirem estruturas isoméricas. A presença de isómeros pode ter importante impacto nas propriedades biológicas dos radiofármacos, já que estes isómeros apresentam frequentemente diferenças aos níveis da lipofilicidade e da biodistribuição [9].

Resumindo, o ${ }^{99 \mathrm{~m}} \mathrm{Tc}$ origina complexos muito diversos do ponto de vista estrutural, com diferentes estados de oxidação, com números de coordenação que variam de 4 a 7 , o que permite uma química muito rica com imensas possibilidades de síntese de novos compostos. Ao longo das últimas décadas foram muitos os radiofármacos de ${ }^{99 m} \mathrm{Tc}$ desenvolvidos e aprovados para utilização clínica, e um número elevado de novos compostos deste radioisótopo encontra-se actualmente em fase pré-clínica. Virtualmente não existirá nenhuma função ou processo patológico, da imagem de neuroreceptores à oncologia, que não possa ser visualizado com recurso a compostos de ${ }^{99 \mathrm{~m}} \mathrm{Tc}$.

Tais como os outros radiofármacos também os radiofármacos de ${ }^{99 m}$ Tc podem ser classificados em duas grandes categorias: aqueles cuja biodistribuição só depende das suas propriedades físico-químicas, como carga, peso molecular, e um exemplo é o [ ${ }^{99 \mathrm{~m}} \mathrm{Tc}$ ] HMPAO (Figura 2), utilizado em estudos de perfusão cerebral [12] e aqueles cuja biodis-

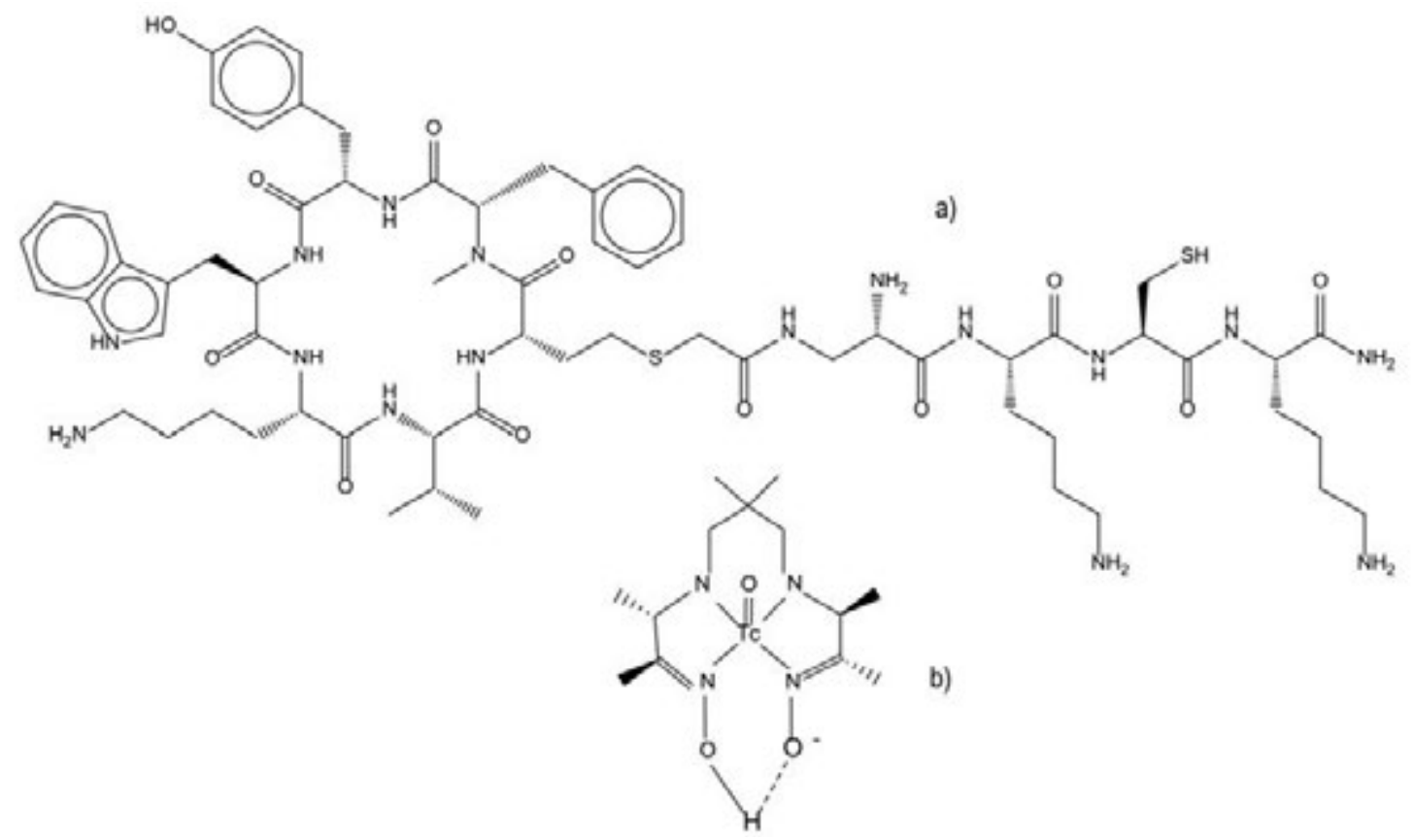

Figura 2 - Estrutura a) do ligando bioconjugado depreótido e b) do [ $\left.{ }^{99 m} \mathrm{Tc}\right] \mathrm{D}, \mathrm{L}-\mathrm{HMPAO}$ 
tribuição depende, por exemplo, da ligação a receptores, como é o caso do [ ${ }^{99 \mathrm{~m}} \mathrm{Tc}$ ]depreótido (Figura 2), em que um quelato de ${ }^{99 m}$ Tc é conjugado a um peptídeo que possui elevada afinidade para receptores da somatostatina sobre-expressos nalguns tipos de tumores [13] (este assunto será tratado mais à frente neste artigo).

Para terminar esta breve abordagem aos radiofármacos de ${ }^{99 m}$ Tc convém frisar que a facilidade com que os hospitais podem dispor de geradores ${ }^{99} \mathrm{Mo} /{ }^{99 m}$ Tc está estritamente dependente da existência e produção de ${ }^{99} \mathrm{Mo}$, um produto da fissão do urânio. Nos últimos anos a comunidade internacional de Medicina Nuclear tem seguido com preocupação a diminuição de ${ }^{99} \mathrm{Mo}$ disponível, já que este apenas é produzido em muito poucos ciclotrões a nível mundial (apenas um na Europa) e estas ultra-sofisticadas e dispendiosas plataformas nucleares começaram a acusar problemas de envelhecimento, originando uma crise de ${ }^{99 m}$ Tc "shortage".

\section{Radiolsótopos e Química de CoordenaÇÃo do Gálio E DO ÍNDIO}

Existem três radionuclídeos de gálio $\left({ }^{66} \mathrm{Ga},{ }^{67} \mathrm{Ga},{ }^{68} \mathrm{Ga}\right)$ e dois radionuclídeos de índio ( ${ }^{111} \mathrm{In}$ e ${ }^{113} \mathrm{In}$ ) com características físicas apropriadas à sua utilização em Medicina Nuclear [14]. Apesar do $\mathrm{Ga}^{3+}$ ou do $\mathrm{In}^{3+}$ apresentarem diferentes radioisótopos, a química dos diversos isótopos de um mesmo elemento é exactamente a mesma e, por isso, podemos marcar uma molécula com, por exemplo, ${ }^{67} \mathrm{Ga}$ ou ${ }^{68} \mathrm{Ga}$ sem que as propriedades químicas dos quelatos obtidos sejam distintas.

$\mathrm{O}{ }^{67} \mathrm{Ga}\left(\mathrm{t}_{1 / 2}=78,1 \mathrm{~h}\right)$ é produzido num ciclotrão a partir do ${ }^{68} \mathrm{Zn}$ enriquecido e depois separado por extracção por solventes ou por troca iónica. $\mathrm{O}^{66} \mathrm{Ga}$, emissor de positrões $\left(\mathrm{t}_{1 / 2}\right.$ = 9,45 h) é também produzido em ciclotrão a partir do ${ }^{66} \mathrm{Zn}$. Existem muito poucos exemplos da utilização deste último radioisótopo. $\mathrm{O}^{68} \mathrm{Ga}$, emissor de positrões, é produzido num gerador ${ }^{68} \mathrm{Ge} /{ }^{68} \mathrm{Ga}$. O longo período do ${ }^{68} \mathrm{Ge}\left(\mathrm{t}_{1 / 2}=280\right.$ dias) permite a obtenção de ${ }^{68} \mathrm{Ga}$ in situ, sem necessidade de se recorrer a um ciclotrão. $\mathrm{O}{ }^{68} \mathrm{Ga}$ tem um período de 67,7 minutos, compatível com a biocinética de muitos radiofármacos de peso molecular baixo ou intermédio, tais como peptídeos ou oligonucleotídeos [15]. As propriedades químicas do ${ }^{68} \mathrm{Ge}$ e do ${ }^{68} \mathrm{Ga}$ são bastante diferentes e permitem uma eficiente separação dos dois radionuclídeos. Estão descritas na literatura duas estratégias principais de separação do ${ }^{68} \mathrm{Ga}$ do ${ }^{68} \mathrm{Ge}$ :

1 - Utilizando matrizes orgânicas contendo grupos fenólicos com os quais o ${ }^{68} \mathrm{Ge}^{4+}$ estabelece ligações bastante fortes e que permitem a eluição do ${ }^{68} \mathrm{Ga}^{3+}$ com uma solução de $\mathrm{HCl}$ [16];

2 - Utilizando matrizes de óxidos inorgânicos tais como $\mathrm{Al}_{2} \mathrm{O}_{3}, \mathrm{SnO}_{2}, \mathrm{Sb}_{2} \mathrm{O}_{5}, \mathrm{ZrO}_{2}$, e TiO 2 e como eluentes soluções de $\mathrm{HCl}$ ou de EDTA [17].

No entanto, independentemente do gerador seleccionado, há problemas a resolver para uma eficiente obtenção de ra- diofármacos de ${ }^{68} \mathrm{Ga}$ : a contaminação do eluato com ${ }^{68} \mathrm{Ge}$ (o mesmo se aplica aos geradores ${ }^{99} \mathrm{Mo} /{ }^{99 m} \mathrm{Tc}$, em que é necessário reduzir ao mínimo a quantidade de ${ }^{99}$ Mo no eluato), o volume do eluato, a lenta cinética de complexação, e ainda a potencial presença de impurezas metálicas tais como $\mathrm{Zn}^{2+} \mathrm{Ti}^{4+}$, e $\mathrm{Fe}^{3+}$, que podem competir com ${ }^{68} \mathrm{Ga}^{3+}$ para $\mathrm{o}$ ligando, dificultando a complexação deste último. Este assunto tem sido muito estudado e têm sido apresentadas várias estratégias para superar estes inconvenientes: desde a utilização de colunas de troca iónica para eliminar as impurezas metálicas (não esquecer a extrema diluição em que se trabalha que faz com que as impurezas possam estar mais concentradas que o próprio ${ }^{68} \mathrm{Ga}^{3+}$ ) e reduzir o volume do eluato, até à utilização de micro-ondas para aumentar o rendimento e a velocidade de complexação [18-19].

Foram recentemente introduzidos no mercado dois tipos diferentes de geradores, um em que a separação ${ }^{68} \mathrm{Ge} /{ }^{68} \mathrm{Ga}$ é realizada numa coluna de $\mathrm{TiO}_{2}$ utilizando como eluente uma solução de $\mathrm{HCl}$ 0,1 M e um outro utilizando uma coluna de $\mathrm{SnO}_{2}$ e como eluente uma solução de $\mathrm{HCl}$ 0,6 M [20].

O radioisótopo mais comum do In é o ${ }^{111} \mathrm{In}\left(\mathrm{t}_{1 / 2}=67,2 \mathrm{~h}\right)$; é produzido num ciclotrão a partir do ${ }^{111} \mathrm{Cd}$, e a separação do ${ }^{111} \mathrm{In}$ do ${ }^{111} \mathrm{Cd}$ faz-se pelos mesmos processos utilizados para isolar o ${ }^{67} \mathrm{Ga}$. A química de coordenação do gálio e do índio tem merecido grande interesse [14,19,21]. O gálio e o índio são metais do grupo 13 da Tabela Periódica e, em condições fisiológicas, existem apenas no estado de oxidação +3. Este facto é determinante no que respeita à síntese de radiofármacos. Estes dois metais são classificados como "ácidos duros” e formam preferencialmente ligações com bases de Lewis iónicas e não polarizáveis tais como ligandos com átomos coordenadores de azoto e oxigénio (grupos amina, carboxilato, fosfonato e fenolato). A química de coordenação do $\mathrm{Ga}^{3+}$ é muito semelhante à do $\mathrm{Fe}^{3+}$, o que tem importantes implicações no que respeita à sua utilização na preparação de radiofármacos. $\mathrm{O} \mathrm{In}^{3+}$, devido ao seu maior raio iónico, tem uma química de coordenação comparável à do $\mathrm{Y}^{3+}$ e dos lantanídeos.

Em solução aquosa os catiões hidratados $\mathrm{Ga}^{3+}$ e $\operatorname{In}^{3+}$ são apenas estáveis em condições acídicas, ocorrendo hidrólise por elevação do $\mathrm{pH}$, com formação dos hidróxidos insolúveis $\mathrm{Ga}(\mathrm{OH})_{3}$ e $\mathrm{In}(\mathrm{OH})_{3}$ que dificultam a preparação de radiofármacos. Por essa razão utilizam-se usualmente, nas reacções de complexação destes dois catiões, soluções tampão com valores de $\mathrm{pH}$ relativamente baixos [22].

\subsection{LIGANDOS PARA GÁlIO E ÍndIO}

De acordo com as suas características estruturais os ligandos utilizados para coordenar os iões metálicos com interesse biomédico podem dividir-se em dois grandes grupos: os ligandos de cadeia linear e os ligandos macrocíclicos. Muitos ligandos possuem, para além dos locais de ligação ao metal, grupos funcionais $\left(-\mathrm{NH}_{2}\right.$ ou $\left.-\mathrm{COOH}\right)$ que permitem a ligação a uma macromolécula. O DTPA, ácido dietilenotriaminapentaacético, é um exemplo de ligando de cadeia linear que tem tido ampla utilização em 
radiofarmácia, nomeadamente na marcação de anticorpos com radiometais (ver secção anticorpos e peptídeos). A conjugação a aminoácidos faz-se normalmente através do derivado bis-anidrido cíclico do DTPA (cDTPA) (Figura 3) [23]. Este método tem como inconveniente o sacrifício de um dos grupos carboxilato do DTPA para formar uma ligação amida com o resíduo do aminoácido da cadeia lateral do anticorpo ou do peptídeo diminuindo a estabilidade termodinâmica do quelato.

Ligandos macrocíclicos são, por definição, ligandos polidentados cíclicos contendo os átomos dadores incorporados no anel e/ou em grupos ligados ao esqueleto do anel. Formam complexos de elevada estabilidade e apresentam maior especificidade e selectividade para os catiões, bem como uma cinética mais lenta de formação e dissociação dos complexos em relação aos seus congéneres lineares. A estabilidade destes quelatos depende da relação entre o tamanho da cavidade do macrociclo e o raio iónico do metal, da rigidez do ligando e da natureza dos grupos coordenadores. Em particular, o ligando 1,4,7-triazaciclononano-1,4,7-triacetato (NOTA) (Figura 3) forma quelatos de elevada estabilidade com o $\mathrm{Ga}^{3+}$ [24].

No entanto, mais do que a estabilidade termodinâmica importa, para a utilização in vivo, a estabilidade cinética do complexo, protegendo o metal de ligandos competidores. Com efeito, o gálio(III) e o ferro(III) têm uma química muito semelhante: carga, raio iónico (62 pm e 65 pm, respectivamente) e preferência pelo número de coordenação seis. Na transferrina, uma proteína que transporta ferro e que existe em concentrações elevadas no plasma $\left(2,5 \times 10^{-3}\right.$ M) existem dois locais de ligação para este ião que também têm elevada afinidade para o $\mathrm{Ga}^{3+}$ (constante de ligação do gálio à transferrina $\operatorname{logK}(\mathrm{Ga}-\mathrm{tf})=20,3$ [25]). Assim, quando se injecta ${ }^{67} \mathrm{Ga}^{3+}$ na forma de complexos pouco estáveis, mais de $90 \%$ deste metal é complexado pela transferrina.

Nos radiofármacos de ${ }^{111} \mathrm{In}^{3+}$, devido ao maior raio iónico deste metal (81 pm) e também ao maior número de co- ordenação, sete, preferem-se derivados do macrociclo octadentado DOTA (1,4,7,10-tetraazaciclododecano-N,N', N',N','-tetraacetato) (Figura 3), por formarem complexos mais estáveis com este metal [26].

\subsection{Radiofármacos de Gálio e ÍndIO}

$\mathrm{O}^{67} \mathrm{Ga}^{3+}$, na forma de citrato de gálio, foi durante muitos anos utilizado na detecção de processos inflamatórios, mas foi ultrapassado pelo aparecimento de radiofármacos de ${ }^{99 m}$ Tc e de outros para PET com a mesma aplicação. O mesmo se diz dos radiofármacos de ${ }^{111} \mathrm{In}^{3+}$ : trata-se de um radionuclídeo que foi muito utilizado na marcação de peptídeos (vide infra) mas a proliferação de centros PET fez com que fosse substituído com grande vantagem pelo ${ }^{68} \mathrm{Ga}$.

Com o aumento do número de centros PET e com o reconhecimento da importância que o ${ }^{68} \mathrm{Ga}$ poderá vir a assumir em imagem molecular ressurgiu o interesse em novos ligandos para gálio, nomeadamente quelatos bifuncionais, como se verá quando se tratar da utilização de peptídeos em imagem molecular.

\section{Radiolsótopos e Química de Coordenação do Cobre}

Existem vários radioisótopos de cobre com potencial interesse quer em diagnóstico quer em radioterapia: ${ }^{67} \mathrm{Cu},{ }^{64} \mathrm{Cu}$, ${ }^{62} \mathrm{Cu},{ }^{61} \mathrm{Cu},{ }^{60} \mathrm{Cu}$. Estes radioisótopos possuem propriedades nucleares muito diversas, períodos que vão desde os 9,6 minutos $\left({ }^{62} \mathrm{Cu}\right)$ às $62 \mathrm{~h}\left({ }^{67} \mathrm{Cu}\right)$, decaindo por emissão de positrões e/ou por emissão $\beta^{-}$. Enquanto o ${ }^{67} \mathrm{Cu}$ é utilizado exclusivamente em terapia, do ponto de vista do diagnóstico por imagem o isótopo mais interessante é o ${ }^{64} \mathrm{Cu}$ usado em PET. Devido ao seu período relativamente longo (12,8 h) $0{ }^{64} \mathrm{Cu}$ tem sido utlizado na marcação de biomoléculas que apresentam períodos biológicos prolongados, nomeadamente anticorpos e peptídeos usados em imagem tumoral [5].O radioisótopo ${ }^{64} \mathrm{Cu}$ pode ser produzido num reactor nuclear através da reacção ${ }^{64} \mathrm{Zn}(\mathrm{n}, \mathrm{p}){ }^{64} \mathrm{Cu}$ ou num ciclotrão, seguindo, por exemplo, o mecanismo ${ }^{64} \mathrm{Ni}(\mathrm{p}, \mathrm{n}){ }^{64} \mathrm{Cu}$.

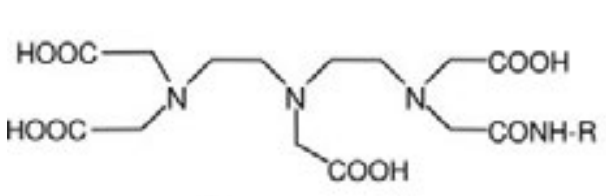

a)

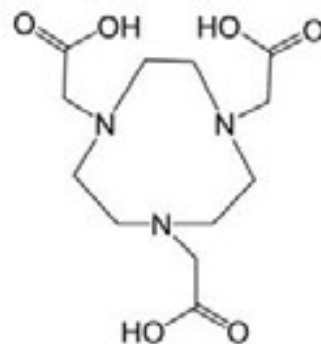

c)

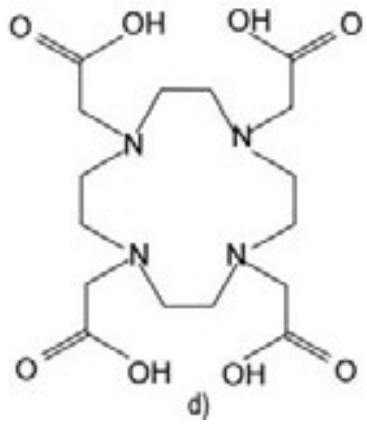

d)

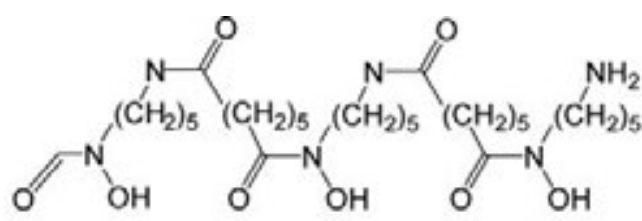

b)

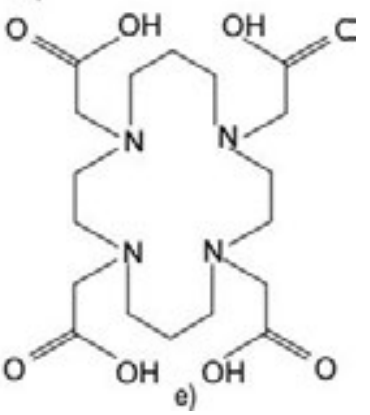

Figura 3 - Ligandos lineares: cDTPA (a) e desferroxamina B (DFO-B) (b); ligandos macrocíclicos: NOTA (1,4,7-triazaciclononano-1,4,7-triacetato) (c), DOTA (1,4,7,10-tetraazaciclododecano-1,4,7,10-tetraacetato) (d) e TETA (1,4,8,11-tetraazaciclotetradecano-1,4,8,11,tetraacetato) (e) 
O cobre apresenta apenas dois estados de oxidação (I e II). O cobre(II), mais utilizado na produção de radiofármacos, prefere nas suas ligações compostos de coordenação contendo átomos de azoto (aminas, bases de Schiff, piridinas) ou de enxofre. Os agentes quelatantes mais utilizados para complexar o cobre, nomeadamente na forma de compostos bifuncionais, são macrociclos e incluem o ácido 4-[(1,4,8,11-tetraazaciclotetradec-1-il)metil]benzóico (CPTA), 1,4,8,11-tetraazaciclotetradecano-1,4,8,11-tetraacetato (TETA) e 1,4,7,10-tetraazaciclododecano-1,4,7,10-tetraacetato (DOTA) (Figura 3) [5,14].

Uma abordagem mais recente à obtenção de radiofármacos de cobre utiliza a denominada química click para incorporar o radioisótopo quer em grupos prostéticos de biomoléculas, quer em quelatos [27]. Estas reacções apresentam elevada estereosselectividade e muito bons rendimentos dando origem a produtos muito puros [27]. Têm a desvantagem de utilizar condições de reacção bastante drásticas, que nem sempre são compatíveis com a estabilidade de biomoléculas mais sensíveis.

\section{Outros Radionuclídeos Metálicos: ${ }^{82} \mathrm{Rb},{ }^{89} \mathrm{Zr},{ }^{44} \mathrm{Sc}$}

Muitos outros radionuclídeos metálicos encontram-se em diferentes fases de investigação e/ou aplicação clínica [7]. No entanto, realçamos aqui o rubídio-88, o zircónio-89 e o escândio-44 por serem mais abundantes na literatura as referências a estes radioisótopos. $\mathrm{O}^{82} \mathrm{Rb}$ é um emissor de positrões e é produzido por um gerador ${ }^{82} \mathrm{Sr} /{ }^{82} \mathrm{Rb}$, o que facilita a sua obtenção. $\mathrm{O}^{82} \mathrm{Rb}^{+}$mimetiza, in vivo, o comportamento do ião potássio, $\mathrm{K}^{+}$, constituindo uma alternativa mais económica ao $\left[{ }^{13} \mathrm{~N}\right] \mathrm{NH}_{3,}$ o traçador PET de perfusão cardíaca [28].

Como muitos processos biológicos possuem semi-vidas relativamente longas, há necessidade de introduzir nos seus traçadores isótopos com maiores períodos de semi-desintegração, como é o caso do ${ }^{44} \mathrm{Sc}\left(\mathrm{t}_{1 / 2}=3,97 \mathrm{~h}\right)$ e do ${ }^{89} \mathrm{Zr}\left(\mathrm{t}_{1 / 2}=78,41 \mathrm{~h}\right) . \mathrm{O}^{44} \mathrm{Sc}$ é também produzido num gerador, ${ }^{44} \mathrm{Ti} /{ }^{44} \mathrm{Sc}$. A química do $\mathrm{Sc}^{3+}$ é similar à dos lantanídeos mas, devido ao seu pequeno raio iónico, assemelha-se também quimicamente ao $\mathrm{Ga}^{3+}$, sendo o DOTA um bom ligando para o ${ }^{44} \mathrm{Sc}$ [29]. Pelo seu lado, o ${ }^{89} \mathrm{Zr}$ tem sido muito utilizado na marcação de anti-corpos. Pode ser produzido em ciclotrões de baixa energia a partir de ítrio metálico através da reacção ${ }^{89} \mathrm{Y}(\mathrm{p}, \mathrm{n}){ }^{89} \mathrm{Zr}$ e o seu período de semi-desintegração corresponde ao período de tempo necessário à biodistribuição de anticorpos intactos (com uma massa aproximada de $150 \mathrm{kDa}$ ). Na conjugação ao anticorpo utiliza-se normalmente o ligando desferrioxamina B (DFO-B) (Figura 3) [30].

\section{Anticorpos e Peptídeos Marcados com Radioisóto- pos Metálicos em Imagem Molecular}

Tal como já foi referido, quelatos bifuncionais são moléculas que possuem uma porção capaz de se ligar a uma molécula bioactiva que por sua vez se liga com elevada afinidade e especificidade a um receptor ou a outra estrutura celular. Os peptídeos e os anticorpos são as moléculas mais utilizadas na vectorização de quelatos bifuncionais e são utilizados não só em diagnóstico como em terapêutica e também em sistemas de transporte de drogas com elevada especificidade.

Anticorpos monoclonais (mAbs) são proteínas com pesos moleculares médios de $160 \mathrm{kDa}$. A marcação destes anticorpos com radioisótopos data do início dos anos 70 do século XX [31]. A maioria dos anticorpos monoclonais utilizados na marcação de tumores pertence à família das imunoglobulinas, IgG. Os anticorpos monoclonais, apesar de apresentarem elevada afinidade e especificidade para um determinado tecido têm, entre outras desvantagens, um desaparecimento lento da corrente sanguínea e lenta fixação no local de interesse, além de uma modesta razão entre a actividade no tecido alvo molecular e a actividade de fundo. Fruto do elevado peso molecular que limita a sua biocinética são necessários grandes intervalos de tempo entre a administração e a obtenção da imagem. Para diminuir estas desvantagens produziram-se fragmentos de mAbs com pesos moleculares de 10 a $100 \mathrm{kDa}$ que conservam as mesmas propriedades biológicas dos precursores intactos e que são habitualmente designados por Fab [32]. Mas estes fragmentos apresentam menor captação tumoral que os seus congéneres intactos. Por essas razões, e porque são extremamente dispendiosos, apenas três desses anticorpos monoclonais têm aprovação para estudos clínicos [33].

A utilização de peptídeos biologicamente activos veio colmatar muitas das desvantagens dos anticorpos e estas moléculas têm merecido um crescente interesse em diagnóstico e terapêutica, especialmente em oncologia [34]. Com efeito, quando comparados com os anti-corpos, os peptídeos, devido ao seu menor tamanho, permitem uma rápida eliminação sanguínea e elevada relação tumor/fundo, são economicamente acessíveis, e não produzem reacções imunológicas. Muitos tumores expressam elevado número de receptores para diferentes peptídeos, e muitos desses receptores medeiam processos de crescimento. Alguns tipos de tumores respondem também a um efeito inibitório induzido in vivo por peptídeos [7], o que se revelou numa importante aproximação clínica ao tratamento de tumores no Homem.

Um obstáculo à utilização de pequenos peptídeos em imagem é a sua rápida degradação plasmática devido à presença de peptidases e proteases endógenas. Por essa razão os peptídeos são modificados de modo a diminuir o seu reconhecimento enzimático, nomeadamente através da introdução de D-aminoácidos ou da introdução de aminoácidos não-usuais [35].

A maioria dos peptídeos com utilização clínica em imagem molecular são análogos da somatostatina. Existem receptores da somatostatina em vários órgãos e tecidos, já que este neuropeptídeo apresenta múltiplas funções fisiológicas. Têm sido utilizados com sucesso em diagnóstico análogos da somatostatina, mas também na terapia (quando marcados com os emissores $\beta^{-},{ }^{90} \mathrm{Y}$ ou ${ }^{174} \mathrm{Lu}$ ) [7] de tumores neu- 
roendócrinos e das suas metástases. O $\left[{ }^{68} \mathrm{Ga}\right]$ DOTATOC e o [ ${ }^{68} \mathrm{Ga}$ DOTANOC (Figura 4), dois análogos da somatostatina marcados com ${ }^{68} \mathrm{Ga}$, têm grande importância no diagnóstico destes tumores a nível mundial [20,36,37] e, como exemplo nacional, no ICNAS (Instituto de Ciências Nucleares Aplicadas à Saúde - Universidade de Coimbra) são realizados cerca de 200 exames/ano utilizando $\left[{ }^{68} \mathrm{Ga}\right]$ DOTANOC.

Têm também sido alvo de investigação outros peptídeos regulatórios para os quais é sabido existirem receptores em vários tipos de tumores, visando a obtenção de novos radiopeptídeos: a hormona estimuladora do melanócito $\alpha$ ( $\alpha$ MSH), peptídeo vasoactivo intestinal (VIP), substância P, colecistoquinina-B (CCK-B), gastrina, neurotensina (NT), bombesina (BN) [31] e mais recentemente uma classe de peptídeos que são marcadores da angiogénese, um processo muito importante em oncologia, os RGDs (a designação vem do facto de o local de ligação ao receptor conter arginina, glicina e ácido aspártico) [38].

As técnicas de marcação de pequenos peptídeos e de anticorpos com radioisótopos metálicos são bastante semelhantes [19,32,36]. Na coordenação são utilizados preferencialmente macrociclos por produzirem quelatos de maior estabilidade cinética e termodinâmica. A exigência de estabilidade é especialmente importante no caso dos anticorpos, já que o seu tempo de permanência no corpo humano é longo. Por outro lado, no caso de peptídeos, moléculas muito mais pequenas do que os anticorpos, a introdução de um macrociclo pode modificar a biodistribuição e, principalmente, a afinidade para o receptor. Por isso se utilizam spacers como mecanismo de diminuir a interacção do quelato metálico com o local de ligação, de modo a existir o mínimo de interferência estereoquímica ou electrónica na ligação específica ao receptor. Mesmo que em quase todos os peptídeos naturais os locais de reconhecimento molecular se encontrem restritos a áreas específicas, o que permite a modificação de outras regiões do peptídeo para marcação com o radioisótopo. Além disso, e já que anticorpos e peptídeos podem produzir efeitos farmacológicos, mesmo quando utilizados em muito baixas concentrações, é fundamental que estas moléculas possuam elevada actividade específica (radioactividade por picomole), de modo a garantir que o radiofármaco não vai produzir actividade biológica. Daí que seja fundamental a optimização da eficiência da marcação com o radioisótopo.

\section{Conclusão}

A imagem molecular tende a ser, cada vez mais, a imagem da expressão génica e proteica [39]. É hoje possível, utilizando a tecnologia e os traçadores correctos, saber quando é que um produto da expressão de um gene, tal como um receptor ou uma enzima, está ou não activo. As técnicas de imagem molecular serão cada vez mais uma preciosa ferramenta quer no diagnóstico, quer na avaliação da resposta à terapia e, certamente, alguns dos radioisótopos hoje em uso, nomeadamente os emissores de positrões ${ }^{68} \mathrm{Ga}$ e ${ }^{64} \mathrm{Cu}$, ganharão ainda maior importância no futuro. Mas outros radioisótopos surgirão, desde que a sua química de coordenação e de conjugação com o vector biológico permita

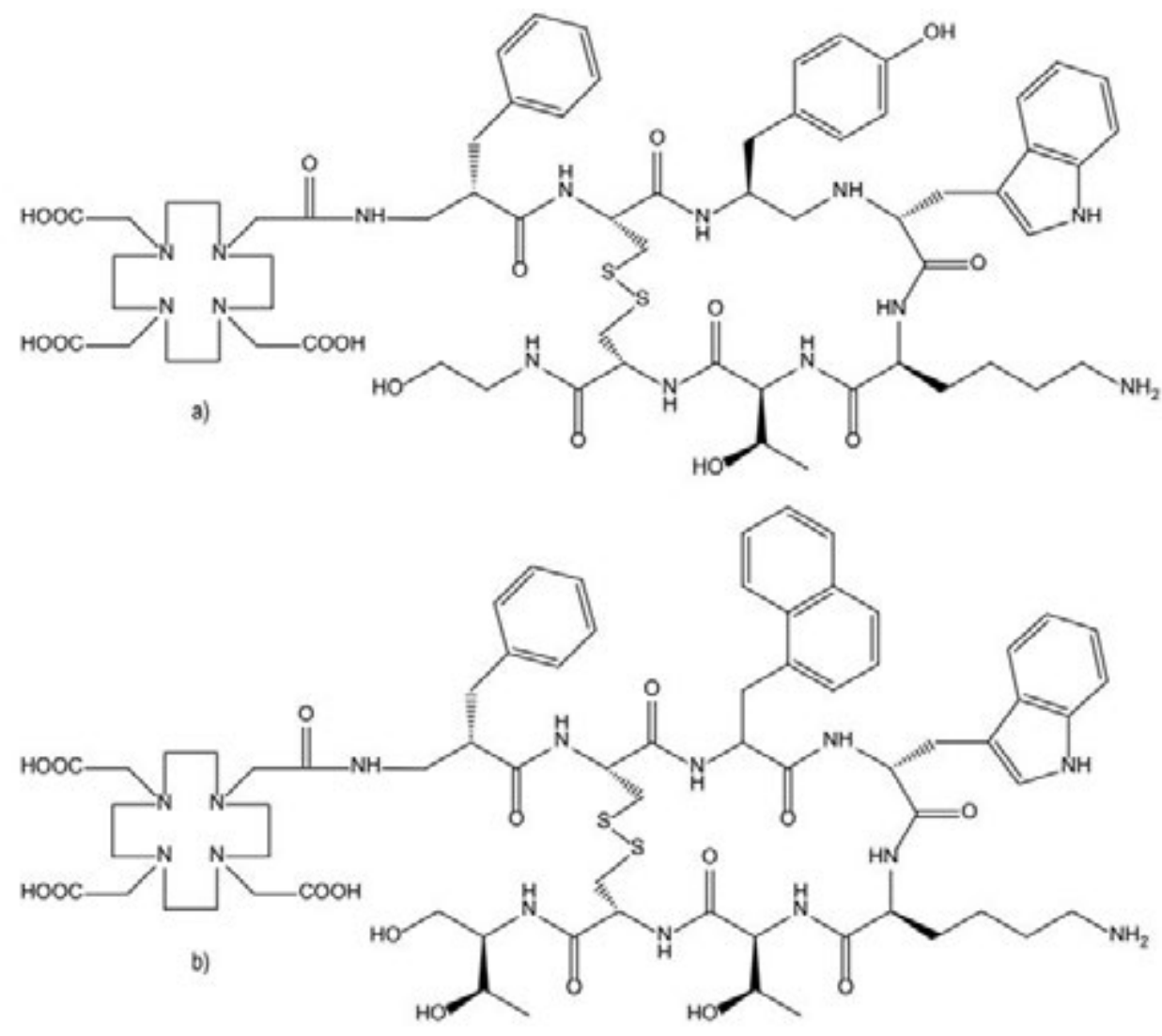

Figura 4 - Estrutura dos peptídeos DOTATOC (a) e DOTANOC (b) 
construir bioconjugados específicos e seguros: cinética e termodinamicamente estáveis em condições biológicas.

\section{BIBLIOGRAFIA}

[1] D.W. Townsend, Ann. Acad. Med. 33 (2004) 133-145

[2] S. Jurisson, J.D. Lydon, Chem. Rev. 99 (1999) 2206-2218

[3] E.W. Price, C. Orvig, Chem. Soc. Rev. 43 (2014) 260-290

[4] J.P. Holland, M.J. Williamson, J.S. Lewis, Mol. Imaging 9 (2010) 1-20

[5] Z. Cai, C.J. Anderson, J. Labelled. Comp. Radiopharm. (2013) DOI: 10.1002/jlcr.3165.

[6] W.A. Volkert, T.J. Hoffman, Chem. Rev. 99 (1999) 22692292

[7] A. Hepeller, S. Froidevaux, A.N. Eberle, H.R. Maecke, Curr. Med. Chem. 7 (2000) 971-994

[8] M. Li, M. Welch, S. Lapi, Mol. Imaging. Biol. 1 (2013) 1-8

[9] M.D. Bartholoma, A.S. Louie, J.F. Valliant, J. Zubieta, Chem. Rev. 110 (2010) 2903-2920

[10] M.A. Mendez-Rojas, B.I. Kharisov, A.Y. Tsivades, J. Coord. Chem. 59 (2006) 1-63

[11] S. Liu, D.E. Scott, Chem. Rev. 99 (1999) 2235-2268

[12] S.F. Sharpp, H.G. Gemmell, D. Lyall, N.T.S. Evans, D. Gvozdanovic, D. Davidson, D.A. Tyrrell, R.D. Picket, R.D. Neirinckk, J. Nucl. Med. 27 (1986)171-177

[13] J.E. Cyr, D.A. Pearson, C.A. Nelson, B.A. Lyons, Y. Zheng, J. Bartis, J. He, M.V. Cantorias, R.C. Howell, L.C. Francesconi, J. Med. Chem. 50 (2007) 4295-4303

[14] C.J. Anderson, M.J. Welch, Chem. Rev. 99 (1999) 2219$-2234$

[15] M.I.M. Prata, Curr. Radiopharm. 1 (2012) 142-149

[16] M. Nakayama, M. Haratake, T. Koiso, O. Ishibashi, K. Harada, H. Nakayama, A. Suggii, S. Yahara and Y. Arano, Anal. Chim. Acta 453 (2002) 135-141

[17] W.A.P. Breeman, A.M. Verbruggen, Eur. J. Nucl. Med. Mol. Imag. 34 (2007) 978-981.

[18] I.Velikyan, G.J. Beyer, B. Langstrom, Bioconj. Chem. 15 (2004) 554-560

[19] H.R. Maecke, J.P. André, Ernst Schering Res. Found Workshop 62 (2007) 215-242

[20] V.H. Alves, M.I.M. Prata, A.J. Abrunhosa, M. CasteloBranco, J. Nucl. Med. 54 (2013) Suppl 2, 1005
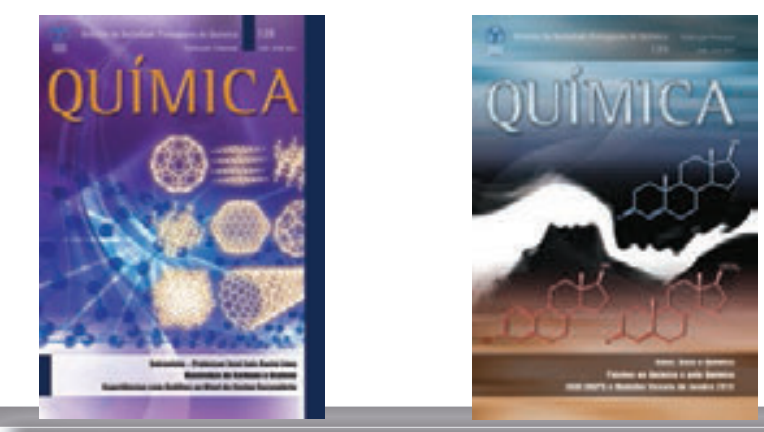

[21] M.A. Green, M.J. Welch, Nucl. Med. Biol. 16 (1989) 435-448

[22] A.F. Martins, M.I.M. Prata, S.P.J. Rodrigues, C.F.G.C. Geraldes, P.J. Riss, A. A. Coarasa, C. Burchardt, C. Kroll, F. Roesche, Contrast Media \& Mol. Imag. 8 (2013) 265-273

[23] D.J. Hnatowich, K.L. Childs, D. Lanteigne, A. Najafi, J. Immun. Meth. 65 (1983) 147-157

[24] E.T. Clarke, A.E. Martell, Inorg. Chim. Acta 181 (1991) 273-280

[25] W.R. Harris, V.L. Pecoraro, Biochemistry 22 (1983) 292-299

[26] J.P. Broan, L. Cox, A.S. Craig, R. Kataky, D. Parker, A. Harrison, M. Randall, G. Ferguson, J. Chem. Soc. Perkin Trans. 2 (1991) 87-99

[27] T.L. Mindt, H. Struthers, L. Brans, T. Anguelov, C. Schweinsberg, V. Maes, D. Tourwé, R. Schibli, J. Am. Chem. Soc. 128 (2006) 15096-15097

[28] Y. Yano, P. Chu, T.F. Budinger, A.E. Ogard, J.W. Barnes, H.A. O’Brien Jr, B. Hoop, J. Nucl. Med. 18 (1977) 46-50

[29] E. Koumarianou, D. Pawlak, A. Korsak, R. Mikolajczak, Nucl. Med. Rev. 14 (2011) 85-89

[30] I. Verel, G.W.M. Visser, R. Boellaard, M. S. Walsum, G. B. Snow, G. A.M.S van Dongen, J. Nucl. Med. 44 (2003)1271$-1281$

[31] D. Pressman, Cancer Res. 40 (1980) 2960-2964

[32] K.O. Webber, R.J. Kreitman, I. Pastan, Cancer. Res. 55 (1995) 318-323

[33] T.E. Witzig, C.A. White, G.A. Wiseman, L.I. Gordon, C. Emmanouilides, A. Raubitschek, N. Janakiraman, J. Gutheil, R.J. Schilder, S. Spies, D.H. Silverman, E. Parker, A.J. Grillo-López, J. Clin. Oncol. 17(1999) 3793-3803

[34] A. Signore, A. Annovazzi, M. Chianelli, F. Corsetti, C. Wiele, R.N. Watherhouse, F. Scopinaro, Eur. J. Nucl. Med. 28 (2001) 1555-1565

[35] J.C. Reubi, J. Nucl. Med. 36 (1995) 1846-1853

[36] W.A. P. Breeman, M. de Jong, E. de Blois, B.F. Bernard, K. Konijnenberg, E.P. Krenning, Eur. J. Nucl. Med. Mol. Imag. 32 (2005) 478-485

[37] D. Wild, H.R. Maecke, B. Waser, J.C. Reubi, M. Ginj, H. Rasch, J. Mueller-Brand, M. Hofmann Eur. J. Nucl. Med. Mol. Imaging 32 (2005) 724-729

[38] A. de Sá, A.A. Matias, M.I.M. Prata, C.F.G.C. Geraldes, P.M.T. Ferreira, J.P. André, Bioorg. \& Med. Chem. Letters 20 (2010) 7345-7348

[39] R. Weissleder, U. Mahmood, Radiology 219 (2001) 316-333

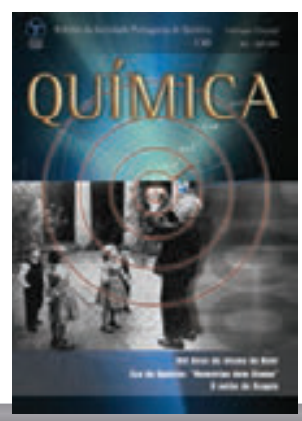

